${ }^{1}$ Laboratory of Applied Geosciences (LGA), Department of Geology, Faculty of Sciences, Mohammed first University, Oujda, Morocco

${ }^{2}$ National Institute of Agronomic Research, Oujda, Morocco

${ }^{3}$ Department of Soil Science and Soil Protection, University of Life Sciences, Prague, Czech Republic

${ }^{4}$ School of Marine Science, Nanjing University of Information Science and Technology, China

${ }^{5}$ Department of Ecotechnologies, National Research Institute of Science and Technology for Environment and Agriculture, Montpellier, France

${ }^{6}$ Department of Mathematics, EDP and Scientific computing Team, Moulay Ismail University, Meknes, Morocco

${ }^{7}$ Department of Inorganic Chemistry, University of Yaoundé I, Yaoundé, Cameroon

\title{
Potential of VIS-NIR spectroscopy to characterize and discriminate topsoils of different soil types in the Triffa plain (Morocco)
}

\begin{abstract}
This study aims to identify the influence of soil organic matter (OM) content and calcium carbonates $\left(\mathrm{CaCO}_{3}\right)$ on soil reflectance and select the optimum spectral bands for discriminating between topsoils of different soil types situated in the irrigated perimeter of the Triffa plain (Morocco) using VIS-NIR reflectance spectroscopy. Soil samples were collected from the plow layer in 26 sampling sites. The spectral measurements were conducted in the field using an ASD Fieldspec portable spectroradiometer (350$2500 \mathrm{~nm}$ ), while the soil samples were analyzed in the laboratory. The spectral data were pre-processed to remove the noise effects and then analyzed with the CovSel (selected covariance) method, validated by linear discriminant analysis in order to select the most optimal spectral variables to discriminate between topsoils of different soil types in the plain. The results of the soils reflectance curves showed that low reflectance intensity marked the soils with high OM contents throughout the VIS spectrum. The influence of the soil OM content was very apparent in the VIS range (between $580-750 \mathrm{~nm}$ ). Regarding the $\mathrm{CaCO}_{3}$ content, it was noted that the soil samples with a high percentage of $\mathrm{CaCO}_{3}$ increase the reflectance in all spectral domains situated between $350 \mathrm{and} 2500 \mathrm{~nm}$. The spectral bands of 1999, 686, 1280, 2340 and $1951 \mathrm{~nm}$ were the most optimal for the soil discrimination in the Triffa plain. This study concluded that the VIS-NIR spectroscopy demonstrates an excellent ability to characterize and discriminate between topsoils in the Triffa plain.
\end{abstract}

Keywords: spectroscopy, linear discriminant analysis, topsoil, soil discrimination, soil reflectance

\section{INTRODUCTION}

The discrimination and physicochemical characterization of topsoil using the traditional laboratory methods in order to extract useful information about the quality and sustainability of soil (such as the soil $(\mathrm{OM})$ content, $\mathrm{CaCO}_{3}$ contents, and texture) is complicated, expensive, requires much time and effort, and provides limited information. Therefore, economical and simple methods for topsoil characterization, analysis and discrimination are needed in the field and laboratory. Currently, visible and nearinfrared (VIS-NIR) spectroscopy represents an alternative method for soil analysis and quantification. The method is faster, non-destructive, environmentally friendly, has a repeatable analytical technique and requires minimal sample preparation (Gholizadeh et al. 2017). Its implementation in the field and laboratory offers the possibility of repeating measurements and estimating the ranges of various soil properties such as $\mathrm{OM}$ content, texture and $\mathrm{CaCO}_{3}$ (Lagacherie et al. 2008, Liu et al. 2017). Several research studies have confirmed the high potentiality of the VIS-NIR spectroscopy to determine and discriminate between soil profiles and to provide information about the influence of soil properties on soil reflectance (Zeng et al. 2016, and Baron et al. 2011) but at present, few or even no, confirmatory studies have been conducted to discriminate between topsoils of different soil types using the data of the VIS-NIR spectroscopy acquired in the field.

The use of VIS-NIR spectroscopy for soil studies started in the 1960-70s (Bowers and Hanks 1965), and the relationship between soil properties and spectral reflectance has been studied and described by many authors (e.g., Stoner and Baumgardner 1980; BenDor et al. 1999). The soil OM and organic constituents of soil have essential influences on soil reflectance 
(Baumgardner et al. 1986). Hoffer and Johannsen (1969) indicated that when the soil OM increases, the soil reflectance decreases in the wavelength ranging from 400 to $2500 \mathrm{~nm}$. In addition, Mathews et al. (1973) found that soil OM correlated well with reflectance in the spectral range situated between 500 and $1200 \mathrm{~nm}$, while Baumgardner et al. (1969) noted that if the soil OM in soil types drops below $2 \%$, then it has only a minimal effect on the reflectance property. Concerning the soil concentration of carbonates, Ben-Dor et al. (1999) mentioned that the carbonates presented in soil play an essential role in the chemical processes of the soil. A study carried out by Cierniewski and Kuśnierek (2010) showed that the influence of $\mathrm{CaCO}_{3}$ on soil reflectance is very apparent in the VIS range between 550 and $700 \mathrm{~nm}$.

For the use of VIS-NIR spectroscopy to discriminate between different soil types, a study made by Viscarra Rossel and Webster (2011) suggested that VIS-NIR spectroscopy could make an important contribution to the definition of soil horizons and classes from their visible-near infrared spectra $(350-2500 \mathrm{~nm})$. Also, it is indicated that the VIS-NIR spectra can be used for the discrimination and identification of Australian soils, particularly those that possess clearly identifiable mineral and organic characteristics because the spectra can be used to measure soil colour, iron oxides, clay minerals, carbonates, and organic matter. In another study carried out by Oliveira et al. (2013) to evaluate the efficiency of VIS-NIR spectroscopy in the analysis of a single taxonomic class of soil and to determine which wavelengths allow soil differentiation on a local scale in Brazil, spectral analysis of data by VIS-NIR spectroscopy combined with PCA (principal component analysis), in particular the first two components, revealed the $700 \mathrm{~nm}$ and $2200-2300 \mathrm{~nm}$ wavelengths to be of interest in discriminating latosols. The particular feature of our study relies on the measurement of soil spectra of the topsoil of different soil types in the field, not in the laboratory as in Viscarra Rossel and Webster (2011) and Oliveira et al. (2013). Also, we used a novel approach suggested by Roger et al. (2011) for selecting the spectral bands that allowed the topsoil differentiation.

The selection of optimal spectral bands using VIS-NIR spectroscopy data in order to discriminate between topsoils is an essential step to facilitate soil mapping and monitoring, in particular for the discrimination between topsoils of different soil types. The

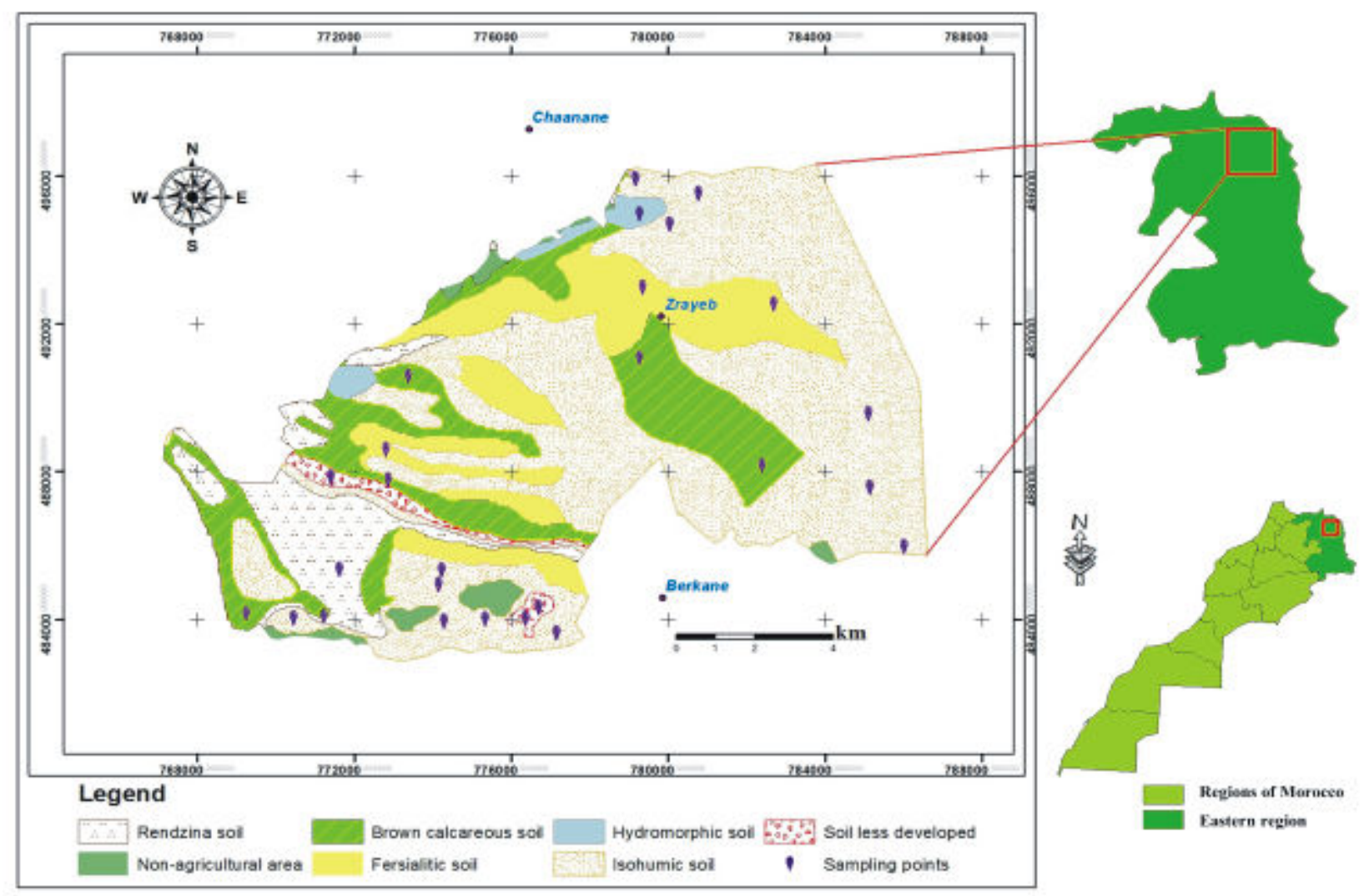

FIGURE 1. Geographical location of the study area in the irrigated perimeter of Triffa plain (north-east of Morocco) 
direct application of classical statistical methods for the analysis of chemometric spectral data is not favorable and reliable because of two major problems: (i) the strong correlation between spectral bands, and (ii) the huge number of variables involved (Roger et al. 2011). Vigneau and Thomas (2012) mentioned that the selected covariance (CovSel) method used for selecting the spectral bands is an efficient technique compared to other selection algorithms such as the partial least square regression (PLSR) and support vector machine.

The main objectives of this work were to evaluate the influence of soil OM and $\mathrm{CaCO}_{3}$ contents on soil reflectance in topsoils of different soil types situated in the irrigated perimeter of the Triffa plain, and to examine the possibility of selecting the most optimal spectral bands to allow discrimination between the different topsoils in the study area, using data from VIS-NIR spectroscopy (350-2500 nm) with the CovSel method and linear discriminate analysis.

\section{MATERIALS AND METHODS}

\section{Study Area}

The irrigated perimeter of the Triffa plain is located in the eastern region of Morocco (longitude $34^{\circ} 56^{`} 32.67^{\prime \prime} \mathrm{N}$; latitude $2^{\circ} 24^{\circ} 05.95^{\prime \prime} \mathrm{W}$ ) and covers an area of 15400 ha at an altitude of 120-200 m above sea level (Fig. 1). The chosen area covers all the soil types situated in the Triffa plain and shows the most representative area for each soil type. According to the classification of soils described by Aubert (1965) and used by the pedological service of Morocco, the study area is characterized by a diversified pedological cover, dominated by isohumic soils occupying more than $55 \%$ of studied soils in this area, and covers almost east and north-east of the perimeter studied. These isohumic soils correspond to thick soils with black to brown color, rich in OM, with a lumpy structure and constituting fertile agricultural lands. The soils are rich in bivalent cations and characterized by a progressively decreasing content of OM profiles, with more clayey horizons at depth (Lazaar 2016). Rendzina soil types are also called calcimagnesian soils. They are developed from calcareous mother rocks, whose OM is rapidly decomposed, and the humidification process is blocked due to the excess of calcium that slows down the phenomenon of alteration (Lazaar 2016). Rendzinas are shallow and stony, do not have a B horizon and are characterized by little translocation of materials. Calcareous brown soils are also developed from calcareous mother rocks with an upper horizon A1 merging into a brighter B horizon, but show no signs of translocated sesquioxides over a paler C horizon (Aubert 1965). The soils contain carbonate material derived from shell fragments or rock and are stony, deep and provide the best agricultural land in the Triffa plain. Red soils, known as fersialitic soils, are fertile, rich in hematite, well drained and structured but very sensitive to wind or water erosion. Hydromorphic soils represented only a limited part of the studied area (Lazaar 2016). The soils are characterized by the reduction or localized segregation of iron, owing to the temporary or permanent waterlogging of the soil pores which causes a lack of oxygen over a long period. Depending on the circumstances, the ferrous iron either accumulates in the profile giving it a greenish (or sometimes bluish) grey colour, or it is mobilized and moves very locally, forming rusty patches or concretions of ferric iron within mineral horizons (Duchaufour 1982). The term of less-developed soils refers to young soils characterized by a low mineral alteration and a low organic matter content, which is generally superposed on the mineral substrate without forming organo-mineral complexes (Lazaar 2016).

\section{Soil sampling and analyses}

The field sampling was carried out during the first week of May 2016. Twenty-six sampling sites were chosen to cover the entire study area, by selecting the most homogeneous and representative area for each type of soil. In the non-root zone of soil $(0-30 \mathrm{~cm})$, 26 soil samples were collected with a mechanical auger and then transported to the laboratory in order to analyze their texture using the densimetry method proposed by the USDA (2017). The $\mathrm{CaCO}_{3}$ content was determined by the Bernard calcimeter method according to the AFNOR NF P 94-048 (1996) norm. The soil OM content was quantified by the modified Walkley-Black technique (Petard 1993), while the soil $\mathrm{pH}$ was measured potentiometrically in distilled water.

\section{Collection and pre-processing of hyperspectral data}

The spectral measurements were conducted in the field using an ASD FieldSpec III spectroradiometer with a wavelength of $350-2500 \mathrm{~nm}$. The measurements were performed between 10:00 am and 4:00 pm in order to gain the benefits of high solar illumination and inclination, which can minimize the effects of shading (Fig. 2). The spectroradiometer is characterized by a spectral resolution of $3 \mathrm{~nm}$ and $10 \mathrm{~nm}$ for the spectral regions $350-1000 \mathrm{~nm}$ and $1000-2500 \mathrm{~nm}$ respectively, and a sampling interval between $1.4 \mathrm{~nm}$ 


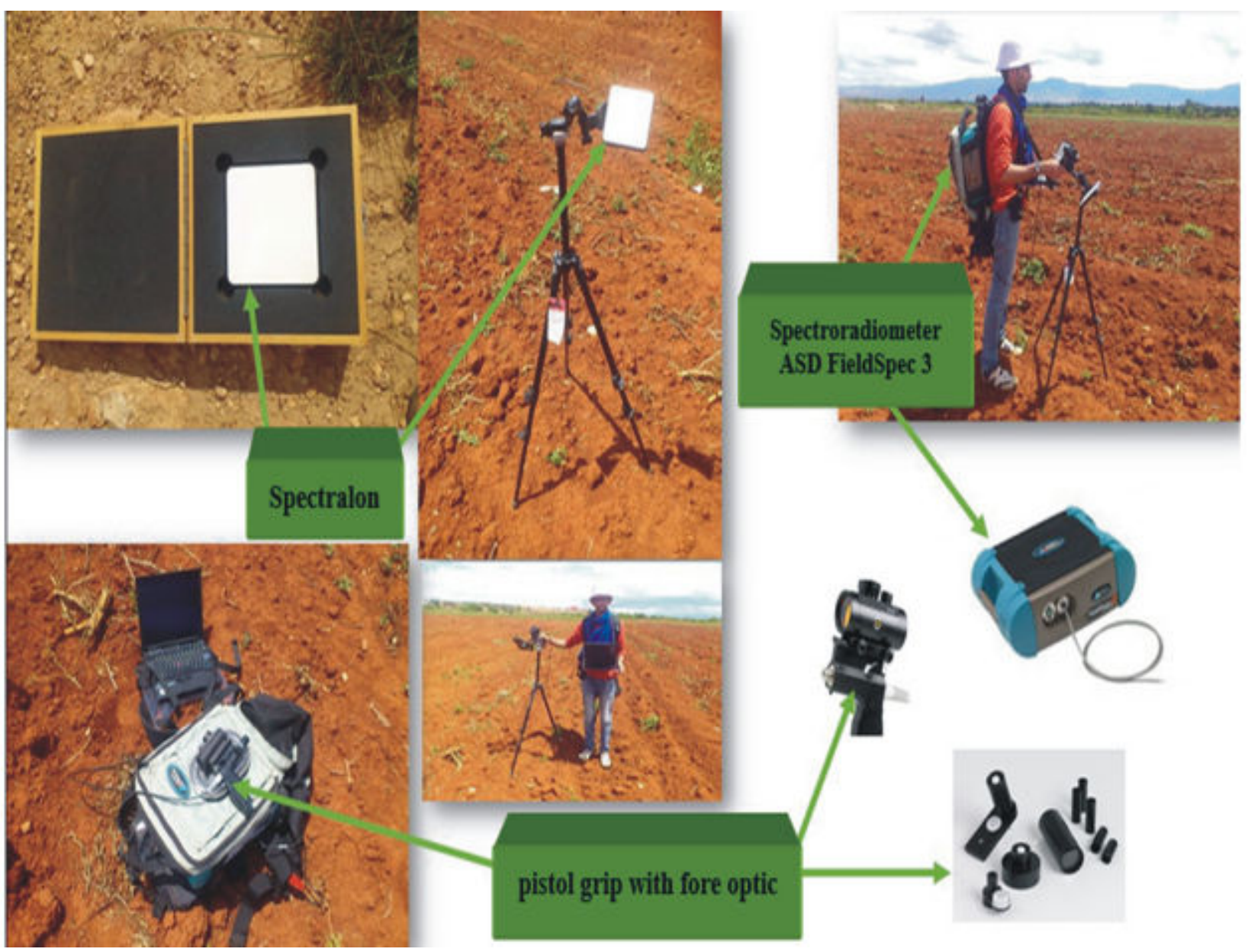

FIGURE 2. The Spectroradiometer ASD Fieldspec III and employed accessories

and $2 \mathrm{~nm}$. The wavelength configuration of the spectroradiometer is organized as the VIS spectral domain (350-700 nm) and the NIR (near infrared) domain (700-2500 $\mathrm{nm}$ ). The scanning time of the instrument is $100 \mathrm{~ms}$ and each spectrum was acquired with an average of 25 measurements. The spectral measurement method was conducted in two successive steps; the first step was to measure the reference reflectance on a spectralon before and after each measurement, and the second was to measure soil reflectance relative to the reference (with a spectralon), using a pistol grip with optical fiber, with repetition a number of times in order to achieve more accurate results.

The spectral data obtained needed several pretreatments, the main objective of this pre-treatment of data being to remove the signal noise and to correct for nonlinearities (Stenberg et al. 2010, Tian et al. 2013). The wavelengths situated in the ranges of $1350-1410 \mathrm{~nm}, 1780-1950 \mathrm{~nm}$, and 2401-2500 nm were eliminated due to the presence of excessive background noise caused by intense atmospheric water absorption (320 spectral bands in total). The SavitzkyGolay smoothing algorithm was used to reduce the noise-spectra and remove additive baseline effects (Savitzky and Golay 1964), and normalization method to eliminate the multiplicative effects (Sauve and Speed 2004). These pre-processing techniques were carried out using the software Chemflow (Chemflow. https://chemproject.org/wakka.php? wiki=PublicationsRessources).

\section{Chemometric analysis}

Regarding the selection of the most optimum spectral bands for discrimination between the topsoils of different soil types situated in the study area, the CovSel approach suggested by Roger et al. (2011) was used. Roger et al. (2011) confirmed that the CovSel method is well adapted to the multi-response calibration of spectrometers and can be applied to the problem of discrimination considering indicator variables as responses. The CovSel technique has been specially designed for spectral bands selection and 
TABLE 1. The Analogy between PLS and CovSel method (Roger et al. 2011)

\begin{tabular}{|c|c|}
\hline PLS & CovSel \\
\hline $\begin{array}{l}j=1 \\
\mathrm{u}_{j}=\operatorname{ArgMax}_{\mathrm{u}}\left(\operatorname{Max}_{\mathrm{v}}\left(\operatorname{cov}(\mathrm{Xu}, \mathrm{Yv})^{2}\right)\right)_{\mathrm{u}^{2}, \mathrm{v}^{2}=1} \\
\mathrm{z}=\mathrm{Xu}_{j} \\
\mathrm{X} \leftarrow \mathrm{P}_{\mathrm{z}}^{\perp} \mathrm{X} \\
\mathrm{Y} \leftarrow \mathrm{P}_{\mathrm{z}}^{\perp} \mathrm{Y} \\
j \leftarrow j+1 \text { go to } 2\end{array}$ & $\begin{array}{l}j=1 \\
I_{j}=\operatorname{ArgMax}_{m}\left(\operatorname{Max}_{\mathrm{v}}\left(\operatorname{cov}\left(\mathrm{Xs}^{m}, \mathrm{Yv}\right)^{2}\right)\right. \\
\mathrm{z}=\mathrm{Xs}^{I_{j}}=\mathrm{x}_{I_{j}} \\
\mathrm{X} \leftarrow \mathrm{P}_{\mathrm{z}}^{\perp} \mathrm{X} \\
\mathrm{Y} \leftarrow \mathrm{P}_{\mathrm{z}}^{\perp} \mathrm{Y} \\
j \leftarrow j+1 ; \text { go to } 2\end{array}$ \\
\hline
\end{tabular}

for the treatment of two common problems, namely: (i) the huge number of variables (spectral bands) that yield a very large solution space, and (ii) the strong correlation between them (Roger et al. 2011). The differences between the PLSR (partial least square regression) method, the most common chemometric technique, and the CovSel approach are given in Table 1. Vigneau and Thomas (2012) mentioned that the CovSel algorithm works in a manner very similar to the successive projection algorithm (SPA). However, the SPA works only in the X-space that is spawned by the spectral bands themselves and aims to minimize the collinearity between the spectral bands selected, while the CovSel method carries out the $\mathrm{X}$-variable selection by also taking into account their covariance with the responses Y. This approach is based on the step-by-step selection of spectral bands with an orthogonal projection between each step to ensure a weak correlation of selected spectral bands (Roger et al. 2011). The advantage of this method is that it is applicable whether the number of samples is large or small. For the spectral bands chosen by the CovSel method, a linear discriminant analysis was applied in order to determine the discriminant weight of each selected spectral band providing the best discrimination between topsoils of different soil types in the Triffa plain.

\section{RESULTS AND DISCUSSION}

\section{Soil characteristics}

The descriptive statistics of four soil properties, namely $\mathrm{pH}, \mathrm{CaCO}_{3}, \mathrm{OM}$ and texture are summarized in Table 2. The difference between the maximum and minimum values for the concentrations of these elements in the topsoils of different soil types of the study area demonstrates that.

The $\mathrm{CaCO}_{3}$ content in the studied soil types ranged from $1.51 \%$ to $49.85 \%$ with an average value of $13.8 \%$, indicating that, according to the AFNOR NF P 94-048 (1996) for soil classification, the soils of the study area generally belonged to the slightly to
TABLE 2. Descriptive statistics of soil properties in the studied sample sets

\begin{tabular}{lccccc}
\hline $\begin{array}{l}\text { Soil } \\
\text { parameters }\end{array}$ & Minimum & Maximum Mean & $\begin{array}{l}\text { Standard } \\
\text { deviation }\end{array}$ & Variance \\
\hline $\mathrm{pH}$ & 6.1 & 7.7 & 7.1 & 0.30 & 0.095 \\
\hline $\mathrm{CaCO}_{3}(\%)$ & 1.5 & 49.8 & 13.8 & 11.9 & 142.9 \\
\hline $\mathrm{OM} \mathrm{( \% )}$ & 0.7 & 3.4 & 2.1 & 0.6 & 0.400 \\
\hline Clay $(\%)$ & 0 & 12.5 & 5.6 & 3.6 & 13.2 \\
\hline Silt (\%) & 24.6 & 79.9 & 60.7 & 13.2 & 175.8 \\
\hline Sand (\%) & 12.6 & 70.3 & 33.6 & 12.6 & 161.2 \\
\hline
\end{tabular}

moderately calcareous soil classes. In term of $\mathrm{pH}$, the soils in the Triffa plain are characterized by $\mathrm{pH}$ values varying between 6.12 and 7.72 ; however, the analyzed soil samples had values mostly higher than 7 , which is due to the excess of $\mathrm{CaCO}_{3}$ content in the different soils caused by the dissolution of the calcareous rock in which the different soil types were developed. Corresponding to the classification of Ruellan (1971), the soil types of the study area are generally basic.

Concerning the results of the OM content for the soil samples analyzed, it is shown that the percentage of soil OM content varies between 0.74 and $3.44 \%$, with the percentage of clay fraction never exceeding $10 \%$. These analyses led us to conclude that the different topsoils of the study area are characterized by low to medium values of OM content such as rendzina, less-developed, hydromorphic, and fersialitic soils, while other soils such as the isohumic and brown calcareous soils are rich in OM content. On the other hand, it was noted that the soils situated towards the southwest of the study area (rendzina soils) are characterized by low OM content, which is related to the high content of $\mathrm{CaCO}_{3}$ in these soils. Equally, another factor for the lower OM content of these soils is the fact that the farmers burn the agricultural land, which leads to the steppization processes (steppization: the phenomenon of the migration of the OM to lower horizons of soil caused by the high leaching of the clay fraction, which makes the structure coarser in the depths of the soil). For the results of particle size (texture) analysis, it was indicated that 


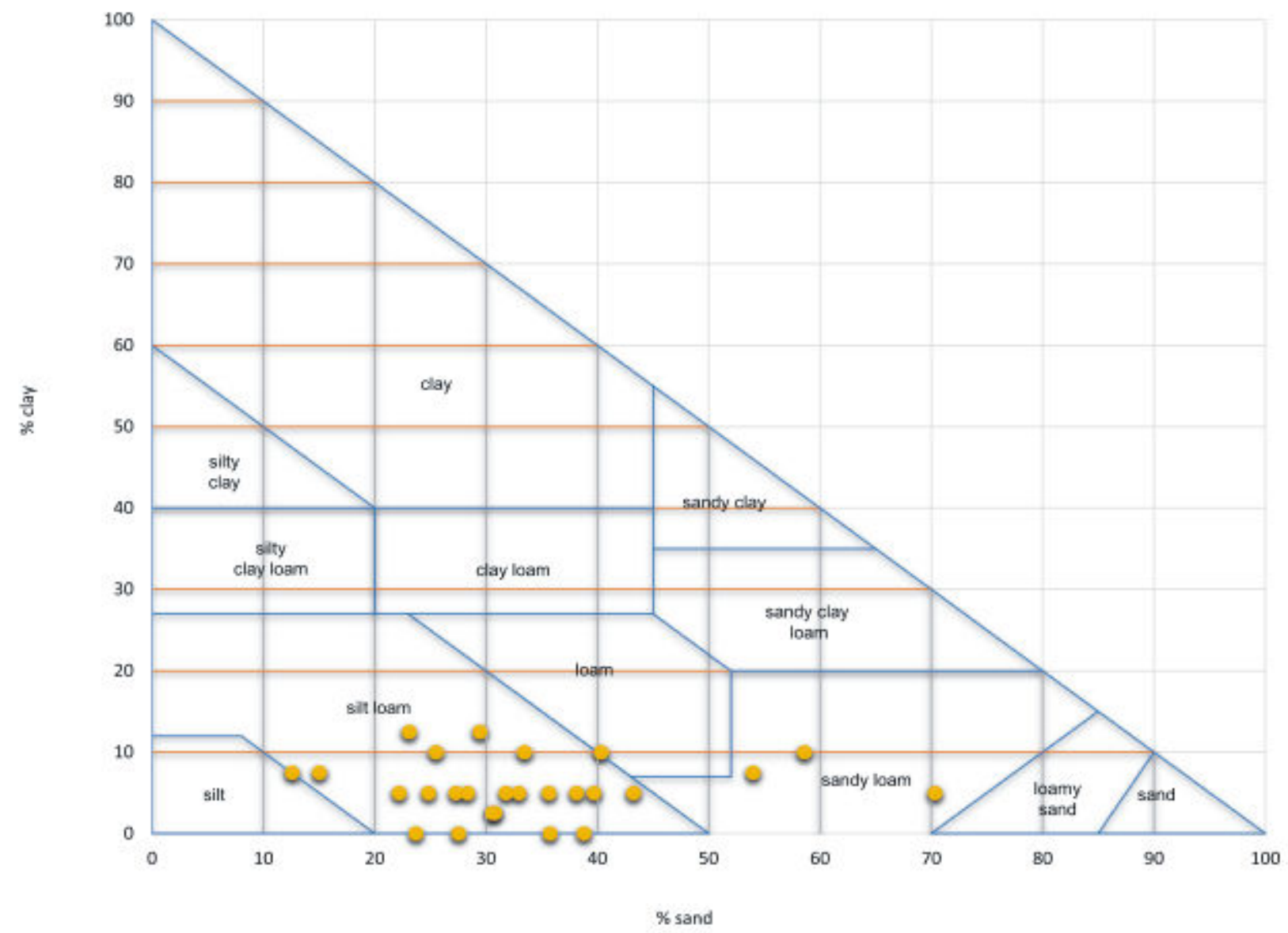

FIGURE 3. The soils texture of the studied area in the textural triangle (USDA, 1996)

the percentage of the silt and sand fractions were more abundant compared to the clay fraction in all soil samples. The results of the projection of the different fractions of soil samples (clay, silt, and sand) on the textural triangle according to the USDA norm (2017) are shown in Figure 3. The textural triangle showed that the soil samples of the study area were mostly characterized by the dominance of the silty-loam texture. Finally, these results suggested that most topsoils of the different soil types of the study area was dominated by a silt-loam texture.

\section{Effects of selected soil properties on soil reflectance}

The spectra of soil samples measured in the field with the ASD Fieldspec spectroradiometer are plotted in Figure 4. In general, the VIS-NIR spectra of the topsoils of different soil types have a similar reflectance shape in which the reflectance is lower in the VIS range (400-700 nm) and is higher in the NIR range (701-2500 $\mathrm{nm})$, with the presence of several absorption bands of different intensities around 1400, 1900 , and $2200 \mathrm{~nm}$. The complex bands observed in the NIR range situated at $1350-1416 \mathrm{~nm}, 1789-1950 \mathrm{~nm}$ and 2400-2500 nm are caused by intense atmospheric water absorption (Cozzolino and Morón 2003). The differences between the reflectance curves of the different topsoils in the spectral range 350-2500 nm were mainly due to the nature and primary properties of soil samples, such as the texture, $\mathrm{CaCO}_{3}$ content, and OM content. This was confirmed by the average results obtained from the analysis of soil properties of topsoil in the laboratory (Table 3). The comparison between the soil reflectance curves and the effects of the selected soil properties of topsoil indicated that the rendzina and less-developed soils had a higher intensity reflectance, reaching a maximum of 0.509 for rendzina soils and 0.424 for less-developed soils in the NIR range at $1670 \mathrm{~nm}$, compared to other soil types. According to the laboratory results, this high reflectance of rendzina and less-developed soils is due to three parameters: (i) the high calcium carbonates content in these soils, since they are developed from calcareous rocks in which the alteration of the latter favored the enrichment of the soil in calcium carbonates; (ii) the textures of the rendzina and less-developed soil types studied in this zone are characterized 


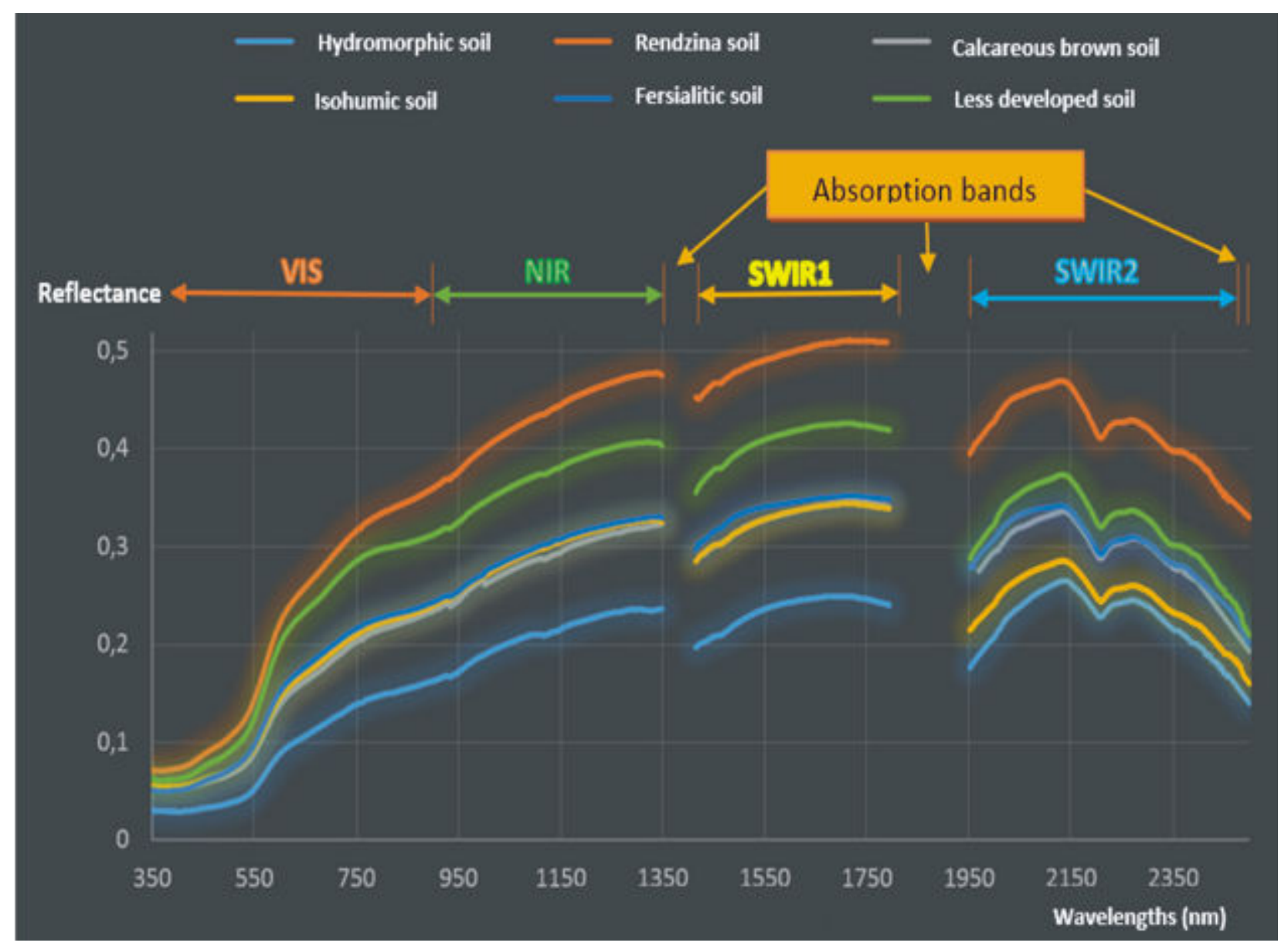

FIGURE 4. Spectral signatures of the six soil types of the study area

TABLE 3. The mean contents of soil $\mathrm{OM}, \mathrm{CaCO}_{3}$, and texture in the studied soil samples

\begin{tabular}{|c|c|c|c|c|c|c|}
\hline \multirow[t]{2}{*}{ Type of soil } & \multirow{2}{*}{$\begin{array}{l}\text { Number } \\
\text { of samples }\end{array}$} & \multirow{2}{*}{ OM (\%) } & \multirow[t]{2}{*}{$\mathrm{CaCO}_{3}(\%)$} & \multicolumn{3}{|c|}{ Particle size fraction $(\%)$} \\
\hline & & & & $\begin{array}{l}\text { Clay } \\
(<0.02 \mathrm{~mm})\end{array}$ & $\begin{array}{l}\text { Silt } \\
(0.02-0.06 \mathrm{~mm})\end{array}$ & $\begin{array}{l}\text { Sand } \\
(0.06-2 \mathrm{~mm})\end{array}$ \\
\hline Isohumic soil & 5 & 2.28 & 10.97 & 5.93 & 54.42 & 39.65 \\
\hline Brown calcareous soil & 5 & 2.20 & 09.23 & 3.50 & 61.84 & 34.66 \\
\hline Fersialitic soil & 5 & 1.93 & 13.64 & 7.08 & 60.17 & 32.75 \\
\hline Less-developed soil & 3 & 1.80 & 26.79 & 5.62 & 66.50 & 27.88 \\
\hline Hydromorphic soil & 3 & 1.86 & 06.70 & 5.00 & 65.45 & 29.55 \\
\hline Rendzina soil & 5 & 1.36 & 30.29 & 7.50 & 55.85 & 36.65 \\
\hline
\end{tabular}

by a silty-loam texture, with a clay fraction that does not exceed 8\%; and (iii) the low OM content of these soil types, which can be due to the high content of $\mathrm{CaCO}_{3}$ that slows down the processes of alteration and hence accelerates the decomposition of soil OM and blocks the process of humification. Concerning the brown calcareous, fersialitic and isohumic soils, it was difficult to differentiate between them based on their reflectance curves because of their overlapping, which is related to the approximation of their soil properties in terms of texture, $\mathrm{CaCO}_{3}$, and soil
OM content. The hydromorphic soils were characterized by a very clear reflectance, which was obviously visible in all spectral domains compared to other soil types.

The effects of soil $\mathrm{OM}$ and $\mathrm{CaCO}_{3}$ contents on soil reflectance can be generally explained as follows for.

The response of the spectral reflectance to the nature and percentage of soil OM content is a known fact and was one of the first common applications in the use of VIS-NIR spectroscopy (Blanco and 
Villarroya 2002). The reflectance curves of different topsoils showed that the topsoils with high OM content such as isohumic, brown calcareous, hydromorphic and fersialitic soils were marked by low reflectance intensities throughout the VIS part of the spectrum. However, the topsoils with low OM content were characterized by a high-intensity reflectance in the VIS range. This demonstrates that the influence of the soil OM content on the soil reflectance was more significant in the VIS spectral range at $580-750 \mathrm{~nm}$. The results found by our study confirmed the studies of Dalal and Henry (1986), Blanco and Villarroya (2002) and Chen et al. (2011), which proved that the VIS domain is the most essential spectrum range for determining the influence of SOM content in the soil. On the other hand, it was noted that the effect of OM content on the reflectance curves of the topsoils with a percentage higher than $2 \%$ (e.g., for isohumic soils and brown calcareous soils) was very important because it can mask other soil constituents. On the contrary, the effect of OM on the reflectance curves of the topsoils with a percentage lower than $2 \%$ (e.g., rendzina soils, lessdeveloped soils, hydromorphic and Fersialitic soils) became less efficient. These results confirmed those obtained by Baumgardner et al. (1969). The variation of topsoil reflectance depending on the $\mathrm{CaCO}_{3}$ content showed that, in the reflectance curves of the topsoils with high $\mathrm{CaCO}_{3}$ content such as rendzina soils and less-developed soils, the reflectance was raised in all spectral domains situated at 350-2500 nm. However, when the $\mathrm{CaCO}_{3}$ content was low in the topsoils (hydromorphic, brown calcareous, fersialitic, and isohumic soils), the reflectance was also low. Similar results were obtained by Cierniewski and Kuśnierek (2010).

\section{STATISTICALANALYSIS OF SPECTRAL DATA}

\section{Selection of spectral bands}

This section presents the results of the CovSel method used to select the spectral bands that allow discrimination between topsoils of different soil types in the study area. This approach, based on the step-by-step selection of the spectral bands with an orthogonal projection between each step to ensure the weak correlation of the selected spectral bands, displayed a positive contribution in agreement with the results of Roger et al. (2011) and Vigneau and Thomas (2012). Table 4 shows the results of the twenty spectral bands selected for the twenty-six soil samples by the CovSel method from the 1830 spectral bands used in the statistical model. The primary results of the spectral bands selected appeared very encouraging and significant. The results showed that it is possible to discriminate between topsoils of different soil types in the Triffa plain in the VIS range for the spectral bands $483 \mathrm{~nm}$ and 686 $\mathrm{nm}$, and in the NIR range for the spectral bands 887 , 936, 1006, 1280, 1417, 1642, 1778, 1951, 1956, 1962, 1999, 2006, 2189, 2283, 2340, 2372, 2384 and 2394 $\mathrm{nm}$. For the choice of the optimum spectral bands among the twenty wavelengths selected by the CovSel method, the application of linear discriminant analysis with cross-validation was necessary in order to obtain a better discrimination between topsoils in the study area with a minimal number of spectral bands.

\section{Linear discriminant analysis of spectral bands selected by the covsel method}

The results of the linear discriminant analysis applied for the twenty spectral bands selected by the CovSel method are summarized in Table 5. The results showed that the five spectral bands 1999, 686, 1280, 2340, and $1951 \mathrm{~nm}$ were sufficient for discriminating between topsoils of different soil types situated in the Triffa plain. Moreover, with the five spectral bands, the discriminant analysis finds a space in which the rendzina, hydromorphic, isohumic, Fersialitic, less-developed and brown calcareous topsoils can be separated with a classification error of $11.33 \%$ and a cross-validation error of $15.67 \%$. This proved that the discrimination model is robust and reliable. Also, the NIR spectral domain represented a relatively higher and better potential for differentiating between all topsoils of different soil types in the Triffa plain, followed by the VIS domain, which

TABLE 4. The spectral variables selectet by the Covsel method

\begin{tabular}{ll}
\hline Spectral domain & Spectral bands selected by CovSel Method \\
\hline Visible range $(350-700 \mathrm{~nm})$ & $483 \mathrm{~nm}, 686 \mathrm{~nm}$ \\
\hline NIR range $(701-2500 \mathrm{~nm})$ & $887 \mathrm{~nm}, 936 \mathrm{~nm}, 1006 \mathrm{~nm}, 1280 \mathrm{~nm}, 1417 \mathrm{~nm}, 1642 \mathrm{~nm}, 1778 \mathrm{~nm}, 1951 \mathrm{~nm}, 1956 \mathrm{~nm}$, \\
& $1962 \mathrm{~nm}, 1999 \mathrm{~nm}, 2006 \mathrm{~nm}, 2189 \mathrm{~nm}, 2283 \mathrm{~nm}, 2340 \mathrm{~nm}, 2372 \mathrm{~nm}, 2384 \mathrm{~nm}, 2394 \mathrm{~nm}$ \\
\hline
\end{tabular}


TABLE 5. The results of the linear discriminant analysis applied to the variables selected by the CovSel method

\begin{tabular}{|c|c|c|c|}
\hline $\begin{array}{l}\text { Number } \\
\text { of spectral } \\
\text { bands } \\
\end{array}$ & $\begin{array}{l}\text { Selected } \\
\text { spectral bands } \\
(\mathrm{nm})\end{array}$ & $\begin{array}{l}\text { Calibration error of the } \\
\text { discriminant analysis (\%) }\end{array}$ & $\begin{array}{l}\text { Error of } \\
\text { cross-valid- } \\
\text { ation }(\%)\end{array}$ \\
\hline 1 & 1999 & 83.83 & 83.83 \\
\hline 2 & 686 & 83.83 & 83.83 \\
\hline 3 & 1280 & 83.83 & 83.83 \\
\hline 4 & 2340 & 83.83 & 83.83 \\
\hline 5 & 1951 & 11.33 & 15.67 \\
\hline 6 & 1642 & 15.67 & 22.67 \\
\hline 7 & 1417 & 11 & 16.67 \\
\hline 8 & 936 & 14 & 17 \\
\hline 9 & 1778 & 12 & 15.33 \\
\hline 10 & 2189 & 9.67 & 14 \\
\hline 11 & 1962 & 9 & 13 \\
\hline 12 & 483 & 8 & 12.67 \\
\hline 13 & 2384 & 9.67 & 13.33 \\
\hline 14 & 2006 & 7 & 10.67 \\
\hline 15 & 1006 & 5.67 & 10.67 \\
\hline 16 & 2372 & 5.67 & 10 \\
\hline 17 & 887 & 5.33 & 8.33 \\
\hline 18 & 1956 & 5 & 9 \\
\hline 19 & 2394 & 5 & 8.33 \\
\hline 20 & 2283 & 4.67 & 7.67 \\
\hline
\end{tabular}

had a reliable potential for discrimination between the six soil types at the wavelength of $686 \mathrm{~nm}$. The NIR spectral domain allows the discrimination between the hydromorphic, rendzina, brown calcareous and less-developed topsoils at the wavelength of 1280 $\mathrm{nm}$, while the discrimination between the isohumic and fersialitic topsoils was not very clear at this wavelength in the NIR spectral domain.

\section{CONCLUSIONS}

This study evaluated the potential of VIS-NIR spectroscopy to identify the effects of soil OM and $\mathrm{CaCO}_{3}$ contents on topsoils reflectance curves, and to discriminate between the topsoils of different soil types situated in the Triffa plain. The following conclusions have been determined according to the results obtained from the paper:

- We conclude that the influence of soil OM content on the reflectance curves of the topsoils in the Triffa plain was well marked and clear in the VIS range between 580 and $750 \mathrm{~nm}$. Meanwhile, the variation in the reflectance intensity curves as a function of $\mathrm{CaCO}_{3}$ content was marked in the entire 350-2500 $\mathrm{nm}$ spectral range.
- It is possible to discriminate between topsoils of different soil types, using the spectral data of VIS-NIR spectroscopy combined with the CovSel method and linear discriminant analysis. It is was shown that the spectral bands $1999,686,1280,2340$, and $1951 \mathrm{~nm}$ were of interest in discriminating topsoils of different soil types in the Triffa plain.

\section{ACKNOWLEDGMENTS}

This work has been supported by the Mohammed First University and the National Institute of Agronomic Research (INRA) of Oujda. I want to thank all people for his help in collecting the soil samples and their analysis in the laboratory.

\section{REFERENCES}

AFNOR NF P 94-048., 1996. Soils: recognition and testingdetermination of Carbonate: Calcimeter method.

Aubert G., 1965. Soil classification: Tables of classes, subclasses, groups and subgroups of soils used by the ORSTOM pedology section. ORSTOM notebook, pedology Series III, 269288.

Baron M., Gonzalez-Rodriguez J., Croxton R., Gonzalez R., Jimenez-Perez R., 2011. Chemometric study on the forensic discrimination of soil types using their infrared spectral characteristics. Applied Spectroscopy 65(10): 1151-1161.

Baumgardner MF., Kristof S., Johannsen CJ., Zachary A., 1969. Effects of organic matter on the multispectral properties of soils. Proceedings of the Indian Academy of Science 79: 413422.

Baumgardner MF., Silva LF., Biehl LL., Stoner ER., 1986. Reflectance Properties of Soils. Advances in Agronomy 38: $1-44$.

Ben-Dor E., Irons JR., Epema GF., 1999. Soil Reflectance. [In:] Manual of Remote Sensing: Remote Sensing for Earth Science (Rencz AN., Ryerson RA., Editors). John Wiley and Sons, New York: 111-188.

Blanco M., Villarroya I., 2002. NIR spectroscopy: a rapidresponse analytical tool. TrAC Trends in Analytical Chemistry 21(4): 240-250.

Bowers S.A., Hanks RJ., 1965. Reflection of radiant energy from soils. Soil Science 100(2): 130-138.

Chen H., Pan T., Chen J., Lu Q., 2011. Waveband selection for NIR spectroscopy analysis of soil organic matter based on SG smoothing and MWPLS methods. Chemometrics and Intelligent Laboratory Systems 107(8): 139-146.

Cierniewski J., Kuśnierek K., 2010. Influence of Several Soil Properties on Soil Surface Reflectance. Quaestiones Geographicae 29(1): 13-25.

Cozzolino D., Morón A., 2003. The potential of near-infrared reflectance spectroscopy to analyse soil chemical and physical characteristics. Journal of Agricultural Science 140(1): 6571.

Dalal RC., Henry RJ., 1986. Simultaneous Determination of Moisture, Organic Carbon, and Total Nitrogen by Near Infrared Reflectance Spectrophotometry. Soil Science Society of America Journal 50(1): 120-123. 
Duchaufour R., 1982. Pedology. Springer, Dordrecht: 480 pp.

Gholizadeh A., Carmon N., Klement A., Ben-Dor E., Borůvka L., 2017. Agricultural soil spectral response and properties assessment: Effects of measurement protocol and data mining technique. Remote Sensing 9(10): 1-14.

Hoffer RM., Johannsen CJ., 1969. Ecological potentials in spectral signature analysis. Remote Sensing Ecology 1-16.

Lagacherie P., Baret F., Feret JB., Madeira Netto J., RobbezMasson J.M., 2008. Estimation of soil clay and calcium carbonate using laboratory, field and airborne hyperspectral measurements. Remote Sensing of Environment 112(3): 825835.

Lazaar A., 2016. The contribution of hyperspectral remote sensing in the soil characterization of the Triffa Plain (Eastern Morocco). Master's thesis, Mohammed First UniversityMorocco: 96 pp.

Liu L., Ji M., Buchroithner M., 2017. Combining Partial Least Squares and the Gradient-Boosting Method for Soil Property Retrieval Using Visible Near-Infrared Shortwave Infrared Spectra. Remote Sensing 9(12): 1-18.

Mathews HL., Cunningham RL., Petersen GW., 1973. Spectral Reflectance of Selected Pennsylvania Soils. Soil Science Society of America 37: 421-424.

Oliveira J.F., Brossard M., Siqueira Vendrame P.R., Stanislas M., Edemar J.C., Robélio L.M., Maria de Fátima G., 2013. Soil discrimination using diffuse reflectance Vis-NIR spectroscopy in a local toposequence. Comptes Rendus Geoscience 345: 446-453.

Petard J., 1993. Methods of Analysis. [In:] Volume 1: Soil Analysis. (O.R.S.T.O.M., Editor). Noumea: 1-200.

Roger JM., Palagos B., Bertrand D., Fernandez-Ahumada E., 2011. CovSel: Variable selection for highly multivariate and multi-response calibration. Application to IR spectroscopy. Chemometrics and Intelligent Laboratory Systems 106(2): 216-223.

Ruellan A., 1971. Soils with a differentiated calcareous profile of the plains of lower Moulouya (Eastern Morocco). Report OROSTOM No. 54, Paris: 295 pp.
Sauve AC., Speed T p., 2004. Normalization, baseline correction and alignment of high-throughput mass spectrometry data. Proceedings Gensips 1-4.

Savitzky A., Golay MJE., 1964. Smoothing and Differentiation of Data by Simplified Least Squares Procedures. Analytical Chemistry 36(8): 1627-1639.

Stenberg B., Viscarra Rossel R.A., Mouazen A.M., Wetterlind J., 2010. Visible and Near Infrared Spectroscopy in Soil Science. Adv Agron 107: 163-215.

Stoner ER., Baumgardner MF., 1980. Physicochemical, Site, and Bidirectional Reflectance Factor Characteristics of Uniformly Moist Soil.

Tian Y., Zhang J., Yao X., Cao W., Zhu Y., 2013. Laboratory assessment of three quantitative methods for estimating the organic matter content of soils in China based on visible/nearinfrared reflectance spectra. Geoderma 202-203: 161-70.

USDA (United States Department of Agriculture), 2017. Soil survey manual. [In:] Agriculture Handbook No. 18 (soil science division staff., editor). Washington: 1-154.

Vigneau E., Thomas F., 2012. Model calibration and feature selection for orange juice authentication by $1 \mathrm{H}$ NMR spectroscopy. Chemometrics and Intelligent Laboratory Systems 117: $22-30$.

Viscarra Rossel R.V., Webster R., 2011. Discrimination of Australian soil horizons and classes from their visible-near infrared spectra. European Journal of Soil Science 62(3): 637647.

Website 1: https://chemproject.org/wakka.php?wiki=Publications Ressources

Zeng R., Zhang GL., Li DC. et al., 2016. How well can VNIR spectroscopy distinguish soil classes? Biosystems Engineering 152: 117-125.

Received: October 20, 2018

Accepted: June 6, 2019

Associated editor: J. Rejman 